\title{
EDITORIAL
}

\section{Bigger numbers needed!}

\author{
H.F. Becker
}

In this issue of the European Respiratory Journal, RoEBUCK et al. [1] assess the effect of Cheyne-Stokes respiration (CSR) on mortality in patients with heart failure. Of the 78 patients, the largest patient group studied so far, CSR was present in 33 $(42 \%)$. After 500 days of follow-up, mortality was increased in patients with CSR, but after a median of 52 months of followup, this difference was no longer present.

Congestive heart failure is one of the leading causes of morbidity and mortality in developed countries and, despite advances in pharmacological therapy, incidence rates are still rising. Ever since the description of apnoeas followed by a waxing and waning breathing pattern (Cheyne 1818 and Stokes 1854), the occurrence of breathing disturbances in chronic congestive heart failure has been recognised in the medical community. However, until a couple of years ago, many may have thought that CSR was a rare condition occurring in a few patients with end-stage heart failure or severe stroke. In fact, several studies published in recent years uniformly demonstrate that CSR is a very common problem in patients with stable congestive heart failure, with prevalence rates ranging $33-40 \%[2,3]$. CSR leads to several unfavourable consequences: hypoxia, arousal from sleep, sympathetic activation, blood pressure surges and susceptibility to cardiac arrhythmia [4-6]. Pulmonary capillary wedge pressure (PCWP), as a likely cause of CSR [7], and right heart load, as a consequence of CSR [8], are increased in heart failure patients with CSR, as compared to those without CSR, despite a comparable reduction of left ventricular ejection fraction in both groups.

The pathophysiological concept to explain CSR in heart failure that has received most attention suggests that hyperventilation due to pulmonary congestion leads to a drop of $\mathrm{CO}_{2}$ pressure below the apnoeic threshold, especially during nonrapid eye movement sleep [9, 10]. Prolonged circulation time and increased ventilatory response to $\mathrm{CO}_{2}$ cause sustained oscillations of breathing [11]. An important finding to support this concept is the almost complete elimination of CSR with supplemental $\mathrm{CO}_{2}[12,13]$.

Given all the above-mentioned negative consequences of CSR, one would expect that mortality in heart failure patients with CSR is higher than in those without CSR. However, studies addressing this hypothesis have shown conflicting results. Out of the six studies with a follow-up period of $\geqslant 2$ yrs that have been published so far, three have reported increased mortality in chronic stable heart failure patients with CSR as compared to those without CSR [14-16]. In contrast, the other three studies $[1,17,18]$, including the one by ROEBUCK et al. [1] published in this issue of the ERJ, observed no increased mortality in patients with CSR.

Which factors contribute to these discrepant results? First of all, the cut-off point for the apnoea/hypopnoea index differed in all studies, mainly because there is no accepted

Correspondence: H.F. Becker, Dept of Pneumologie, University of Marburg, Schlafmed Labor Baldingerstr, 35033, Marburg, Germany. Fax: 49 64212865405. E-mail: hf.becker@mailer.uni-marburg.de "normal value" for CSR. One might speculate that by choosing more severely affected patients, like in the two positive studies by LANFRANCHI et al. [15] and SIN et al. [16], the chances of demonstrating an effect of CSR on mortality increase.

Secondly, statistical methods and end-point definitions varied.

A third contributing factor could be the varying drug treatment throughout the studies. Optimisation of heart failure therapy after the initial sleep study influences the results, because, almost certainly, improved medical treatment reduces CSR [19]. This causes a bias towards a negative result.

The follow-up time is another crucial point. Whereas after 500 days there was a significant difference in mortality in patients with CSR as compared to those without CSR, this effect was no longer present at the end of the study after 52 months. One might argue that severe CSR exerts its negative effects on mortality early on during the follow-up phase, leaving patients without CSR in both groups and thus lead to a similar mortality rate in a sufficiently long follow-up period.

Only the studies by RoEBUCK et al. [1] and by TRAVERSI et al. [18] provide right heart catheter data. Increased PCWP is clearly linked to the occurrence of CSR and is also a known risk factor for mortality in heart failure patients. Thus, even if CSR is a mere consequence of increased PCWP, in sufficiently large studies, CSR should turn out to be related to increased mortality due to the increased PCWP in CSR patients. However, in the study by RoEBUCK et al. [1] this was not demonstrated. This fact emphasises the lack of statistical power despite the largest patient group studied so far.

Finally, let us take a closer look at the number of patients analysed to date. All six studies included a total of only 318 patients, 139 of them with CSR. In the three studies that did suggest an effect of CSR on mortality, a total of 56 patients with CSR were included. Additionally, statistical power calculation has not been reported in any of the studies published so far. Even in the absence of CSR, heart failure patients have a poor prognosis. Multiple complications arising from heart failure itself and possible underlying diseases like coronary heart disease, myocardial infarction, arrhythmia, etc., may lead to death independent of breathing disorders during sleep. Patients on the transplant list will be transplanted if an organ is available and not necessarily because of deterioration of heart failure. Therefore, many confounding factors are present in these patients, making it difficult to detect the effect of a single additional factor like CSR on mortality.

Indeed, the study by RoEBUCK et al. [1] deals with a clinically important question: does CSR increase mortality in chronic heart failure patients? ROEBUCK et al. [1] do not come to the conclusion that this is not the case, but that they did not find a mortality increase after a median follow-up period of $>4$ yrs. They, therefore, conclude that mortality increase has not been proven!

The consequence of their paper should not be diagnostic 
and therapeutic nihilism. We have to admit that the currently available clinical studies are only a drop in the ocean. As a consequence, additional large multicentre trials with sufficient statistical power and optimal design should be initiated to address the gaps in our knowledge. Bigger numbers are indeed needed!

\section{References}

1. Roebuck T, Solin P, Kaye DM, Bergin P, Bailey M, Naughton MT. Increased long-term mortality in heart failure due to sleep apnoea is not yet proven. Eur Respir J 2004; 23: 735-740.

2. Javaheri S, Parker TJ, Liming JD, et al. Sleep apnea in 81 ambulatory male patients with stable heart failure. Types and their prevalences, consequences, and presentations. Circulation 1998; 97: 2154-2159.

3. Sin DD, Fitzgerald F, Parker JD, Newton G, Floras JS, Bradley TD. Risk factors for central and obstructive sleep apnea in 450 men and women with congestive heart failure Am J Respir Crit Care Med 1999; 160: 1101-1106.

4. Naughton MT, Benard DC, Liu PP, Rutherford R, Rankin F, Bradley TD. Effects of nasal CPAP on sympathetic activity in patients with heart failure and central sleep apnea. Am J Respir Crit Care Med 1995; 152: 473-479.

5. Javaheri S, Corbett WS. Association of low $\mathrm{Pa}, \mathrm{CO}_{2}$ with central sleep apnea and ventricular arrythmias in ambulatory patients with stable heart failure. Ann Intern Med 1998; 128: 204-207.

6. van de Borne P, Oren R, Abouassaly C, Anderson E, Somers VK. Effect of Cheyne-Stokes respiration on muscle sympathetic nerve activity in severe congestive heart failure secondary to ischemic or idiopathic dilated cardiomyopathy. Am J Cardiol 1998; 81: 432-436.

7. Solin P, Bergin P, Richardson M, Kaye DM, Walters EH, Naughton MT. Influence of pulmonary capillary wedge pressure on central apnea in heart failure. Circulation 1999; 99: $1574-1579$.

8. Christ M, Grimm W, Rostig S, et al. Association of right ventricular dysfunction and Cheyne-Stokes respiration in patients with chronic heart failure. J Sleep Res 2003; 12: 161-167.

9. Khoo MCK, Kronauer RE, Strohl KP, Slutsky AS. Factors inducing periodic breathing in humans: a general model. J Appl Physiol 1982; 53: 644-659.

10. Francis DP, Willson K, Davies LC, Coats AJ, Piepoli M. Quantitative general theory for periodic breathing in chronic heart failure and its clinical implications. Circulation 2000; 102: 2214-2221

11. Wilcox I, McNamara SG, Dodd MJ, Sullivan CE. Ventilatory control in patients with sleep apnoea and left ventricular dysfunction: comparison of obstructive and central sleep apnoea. Eur Respir J 1998; 11: 7-13.

12. Andreas S, Weidel K, Hagenah G, Heindl S. Treatment of Cheyne-Stokes respiration with nasal oxygen and carbon dioxide. Eur Respir J 1998; 12: 414 419.

13. Steens RD, Millar TW, Su X, et al. Effect of inhaled 3\% $\mathrm{CO}_{2}$ on Cheyne-Stokes respiration in congestive heart failure. Sleep 1994; 17: 61-68.

14. Hanly PJ, Zuberi-Khokhar NS. Increased mortality associated with Cheyne-Stokes respiration in patients with congestive heart failure. Am J Respir Crit Care Med 1996; 153: 272-276.

15. Lanfranchi PA, Braghiroli A, Bosimini E, et al. Prognostic value of nocturnal Cheyne-Stokes respiration in chronic heart failure. Circulation 1999; 99: 1435-1440.

16. Sin DD, Logan AG, Fitzgerald FS, Liu PP, Bradley TD. Effects of continuous positive airway pressure on cardiovascular outcomes in heart failure patients with and without Cheyne-Stokes respiration. Circulation 2000; 102: 61-66.

17. Andreas S, Hagenah G, Möller C, Werner GS, Kreuzer H. Cheyne-Stokes respiration and prognosis in congestive heart failure. Am J Cardiol 1996; 78: 1260-1264.

18. Traversi E, Callegari G, Pozzoli M, Opasich C, Tavazzi L. Sleep disorders and breathing alterations in patients with chronic heart failure. G Ital Cardiol 1997; 27: 423-429.

19. Walsh JT, Andrews R, Starling R, Cowley AJ, Johnston ID, Kinnear WJ. Effects of captopril and oxygen on sleep apnoea in patients with mild to moderate congestive cardiac failure. Br Heart J 1995; 73: 237-241. 